\title{
Prevalence of problematic online gaming among undergraduate medical students and its relation to well-being, self-esteem and depressive mood in Goa, India
}

\author{
Abhishek U. Bicholkar, Amit Dias*, Von Mascarenhas
}

Department of Preventive and Social Medicine, Goa Medical College, Goa, India

Received: 05 December 2018

Revised: 11 January 2019

Accepted: 04 February 2019

\section{*Correspondence:}

Dr. Amit Dias,

E-mail: dr_amit_dias@yahoo.com

Copyright: ( ) the author(s), publisher and licensee Medip Academy. This is an open-access article distributed under the terms of the Creative Commons Attribution Non-Commercial License, which permits unrestricted non-commercial use, distribution, and reproduction in any medium, provided the original work is properly cited.

\begin{abstract}
Background: Online video games are one of the most popular recreational activities irrespective of age, gender and culture. Gaming disorder has been recently included in the $11^{\text {th }}$ Revision of the international classification of diseases (ICD-11). Thus online video game addiction among people is a serious mental health issue and unfortunately, research on this addiction is still in its infancy. Thus the present study examines the prevalence of problematic online gaming among undergraduate medical students and its association with demographic variables, and health-related measures like well-being, self-esteem and depressive mood.

Methods: The present cross-sectional study was conducted among the undergraduate students of Goa medical college using online survey method. Problematic online gaming was assessed using the problematic online gaming questionnaire short form (POGQ-SF). Additionally, well-being was assessed using the satisfaction with life scale (SWLS), self-esteem was assessed using Rosenberg's self- esteem scale (RSES) and depressive mood was assessed using the patient health questionnaire (PHQ-9).

Results: According to POGQ-SF, 8\% of the study participants showed problematic online gaming. It was significantly associated with sex of the study participants, frequency of online gaming, duration of internet use per day and duration of a gaming session.

Conclusions: Playing online games is a widespread activity among undergraduate medical students and a substantial proportion of these students exhibit addictive behaviours with regards to online gaming. Further research in terms of longitudinal studies involving larger samples of general population is needed to throw light on causal relationship between problematic online gaming and related factors.
\end{abstract}

Keywords: Problematic online gaming, Well-being, Self-esteem, Depressive mood

\section{INTRODUCTION}

Online video games first appeared in 1990s and since then online video games have become widely popular and accessible. Nowadays, they are one of the most popular recreational activities irrespective age, gender and culture. ${ }^{1}$ Given the prevalence of internet use and online gaming among youth, there is concern that a subset of
Internet-using youth may exhibit problematic or addictive patterns of internet using and online gaming behaviour. ${ }^{2}$

Video games can be divided into two main groups, online and offline video games - a distinction that can significantly influence player behaviour. Offline video games are generally played alone without external help from any other player and they have a distinct start and finish point. However, online video games are usually 
played simultaneously by players who can communicate with one another in real time, cooperating or competing at will which leads to immediate social comparison. ${ }^{3}$ Because of their inherent structural characteristics, these games do not usually have a fixed end point. Online gamers spend more time gaming than those who play offline games, mostly because of the social nature of these games. They find online games more pleasant and satisfying than offline games and sometimes prefer playing games to real-life activities. ${ }^{4}$

First research article on gaming addiction dates back to 1983, when the first report was published suggesting that video game addiction is a problem for students. ${ }^{5}$ Shortly thereafter, the first empirical study on gaming addiction was published by Shotton, based on Internet gaming addiction self-reports of young male players who claimed they were "hooked" on their games.

Gaming addiction, under the original label of internet gaming disorder, was included as a subtype of internet use disorder in the appendix of DSM-5 as a possible future diagnosis, pending further research. ${ }^{7}$ However, gaming disorder is now included in the 11th Revision of the international classification of diseases (ICD-11) and is defined as a pattern of gaming behaviour characterized by impaired control over gaming, increasing priority given to gaming over other activities to the extent that gaming takes precedence over other interests and daily activities, and continuation or escalation of gaming despite the occurrence of negative consequences. ${ }^{8}$

The present study attempts to estimate the prevalence of problematic online gaming (POG) among undergraduate medical students and its relation to various demographic variables, and health-related measures like self-esteem, social well-being and depressive mood.

\section{METHODS}

The present cross-sectional study was conducted among the undergraduate students and interns of Goa medical college using online survey method over a period of three months from May 2018 to July 2018. The questionnaire was shared with the study population using social media platforms like Whatsapp, Facebook, Twitter and Hike Messenger. It also included brief information about the study and necessary instructions needed to participate in the study.

The questionnaire was shared among all the undergraduate students and interns of Goa medical college. Those who did not give consent or did not complete the questionnaire were excluded from the study. The online survey questionnaire collected major sociodemographic information (age, sex, semester), online gaming habits (e.g., type of games played, frequency of playing, duration of typical gaming sessions) etc.
Problematic online gaming was assessed using the POGQ-SF. It measures six dimensions of problematic use (preoccupation, overuse, immersion, social isolation, interpersonal conflicts, and withdrawal). The 12-item version of POGQ is developed by selecting two items from each factor. Each item is answered on a 5-point likert scale ("'never"' to "always"). A cut-off score of 32 points is considered to classify online gamers as problematic gamers. ${ }^{9}$ The reason for a short- form POGQ was to develop a measure that can be used in survey type research, brief enough to assess more impulsive populations, and which facilitates incorporation into time limited surveys. ${ }^{10}$

Additionally, psychological characteristics, including well-being, self-esteem and depressive mood were assessed using the same survey method. Well-being was assessed using the SWLS, which is a short 5-item instrument designed to measure global cognitive judgements of satisfaction with one's life. Participants indicate how much they agree or disagree with each of the 5 items using a 7-point scale that ranges from 7 strongly agree to 1 strongly disagree. A cut-off score of 20 was considered as neutral and scores above and below 20 as satisfied and dissatisfied respectively. ${ }^{11,12}$

Self-esteem was assessed using RSES. RSES is a selfreported 10-item scale that measures global self-worth by measuring both positive and negative feelings about the self. Items are answered on a 4-point scale ("strongly agree" to "strongly disagree"). Scores range from 1040 , with higher scores indicating higher self-esteem. ${ }^{13}$

Depressive mood was assessed using the PHQ-9. PHQ is not designed to diagnose clinical depression but to assess depressive symptom levels over the past 2 weeks. Items are answered on a 4-point scale ("not at all", to "nearly every day"'). Scores range from 0-27, with higher scores indicating higher depressive mood level. ${ }^{14}$

Ethics clearance was taken from the institutional ethics committee of Goa Medical College. Prior to starting the survey the participants were informed that answering the questionnaire implies they give their full consent to use their responses for the study and for research publication without revealing their identity in any form of media or publication. The students were free to refuse consent to participate. Confidentiality was assured and maintained.

Statistical analysis: Data was entered and analysed using SPSS version 22. Chi-square test was utilized to study association between qualitative variables. Mann-Whitney $\mathrm{U}$ test was used to test group differences between study variables and health-related measures i.e. well-being, self-esteem and depressive mood.

\section{RESULTS}

Of the 250 study participants, 143 (57.2\%) were females and $107(42.8 \%)$ were males. The age of the study 
participants ranged between 17 to 27 years with mean age of $21.22 \pm 1.63$ years. The mean age among female study participants was $21.01 \pm 1.42$ years and the mean age among male study participants was $21.5 \pm 1.86$ years. A majority of study participants i.e. $228(91.2 \%)$ were Goans and 22 (8.8\%) were non-Goans. Table 1 shows the distribution of study participants based on their academic year of MBBS. A high proportion of study participants $108(43.2 \%)$ were interns followed by 77 (30.8\%) who were in their $2^{\text {nd }}$ year of MBBS.

Table 1: Distribution of study participants based on academic year, internet use per day, online gaming frequency and duration of online gaming per day.

\begin{tabular}{|c|c|c|}
\hline Characteristics & Frequency & $\begin{array}{l}\text { Percentage } \\
(\%)\end{array}$ \\
\hline \multicolumn{3}{|l|}{ Academic year } \\
\hline $1^{\text {st }}$ Year & 11 & 4.4 \\
\hline $2^{\text {nd }}$ & 77 & 30.8 \\
\hline $3^{\text {rd }}$ & 54 & 21.6 \\
\hline Internship & 108 & 43.2 \\
\hline Total & 250 & 100.0 \\
\hline \multicolumn{3}{|c|}{ Internet use per day (hour) } \\
\hline Less than 1 & 6 & 2.4 \\
\hline $1-2$ hours & 98 & 39.2 \\
\hline $3-5$ & 92 & 36.8 \\
\hline More than 5 & 54 & 21.6 \\
\hline Total & 250 & 100.0 \\
\hline \multicolumn{3}{|l|}{ Online gaming frequency } \\
\hline Never & 106 & 42.4 \\
\hline $\begin{array}{l}\text { Once or less than once a } \\
\text { month }\end{array}$ & 38 & 15.2 \\
\hline $\begin{array}{l}\text { More than once a month } \\
\text { but less than once a week }\end{array}$ & 40 & 16.0 \\
\hline $\begin{array}{l}\text { More than once a week } \\
\text { but less than daily }\end{array}$ & 34 & 13.6 \\
\hline Daily & 32 & 12.8 \\
\hline Total & 250 & 100.0 \\
\hline \multicolumn{3}{|c|}{ Duration of online gaming per day (hour) $(n=144) *$} \\
\hline Less than 1 & 95 & 65.98 \\
\hline $1-2$ & 33 & 22.91 \\
\hline $2-5$ & 16 & 11.11 \\
\hline Total & 144 & 100.0 \\
\hline
\end{tabular}

As per the distribution of study participants based on duration of internet use per day, a very small proportion of study participants, i.e. $2.4 \%(n=6)$ used internet for less than one hour per day. Of the total study participants, $205(82 \%)$ played video games. Of these only 144 $(57.6 \%)$ played online games. Of all the online gamers, only $32(12.8 \%)$ played online games daily (Table 1$)$.

The study showed that those who played online games, $95(65.98 \%)$ played for less than an hour per day, 33 (22.9\%) played for 1-2 hours per day and 16 (11.1\%) played for 2-5 hours per day (Table 1).

According to POGQ-SF, 8\% $(n=20)$ of the study participants showed problematic online gaming. The prevalence of POG was higher i.e. 12.1\% $(n=13)$ among male study participants as compared to female study participants which was $4.9 \%(n=7)$.

The relationships between POG and socio-demographic variables are provided in Table 2. Chi-square analyses revealed that problematic online gaming was significantly associated with sex of the study participants $\left(\chi^{2}=4.38\right.$, $\mathrm{p}=0.036$, OR $(95 \% \mathrm{CI})=2.69(1.03-6.99)$ and frequency of online gaming $\left(\chi^{2}=6.23, \mathrm{p}=0.013\right.$ OR $(95 \% \mathrm{CI})=3.11$ $(1.23-7.85)$.

Chi-square test with yates correction revealed that problematic online gaming was significantly associated with duration of internet use per day $\left(\chi^{2}=6.33, \mathrm{p}=0.016\right.$, OR $(95 \% \quad \mathrm{CI})=4.43(1.27-15.56)$ and duration of a gaming session $\left(\chi^{2}=50.32, \quad \mathrm{p}=<0.001, \quad\right.$ OR $\quad(95 \%$ $C I)=23.88(7.52-75.87)$. No significant relationship was observed between problematic online gaming and academic year and current residence of the study participants.

Table 3 shows mean scores of well-being, self-esteem and depressive mood with respect to problematic online gaming among undergraduate students. Using the MannWhitney $U$ test, there was significant group differences with regards to measures of well-being ( $\mathrm{Z}=-1.99$, $\mathrm{p}=0.046)$, self-esteem $(\mathrm{Z}=-2.39, \mathrm{p}=0.017)$, and depressive $\operatorname{mood}(\mathrm{Z}=3.763, \mathrm{p}<0.001)$.

Table 2: Demographic variables and its association with problematic online gaming.

\begin{tabular}{|c|c|c|c|c|}
\hline \multirow{2}{*}{ Demographic variable } & \multicolumn{2}{|c|}{ Problematic online gaming } & \multirow{2}{*}{ Chi-square (p value) } & \multirow{2}{*}{ OR $(95 \% \mathrm{CI})$} \\
\hline & Present & Absent & & \\
\hline \multicolumn{3}{|l|}{ Sex } & \multirow{3}{*}{$4.376(0.036)$} & \multirow{3}{*}{$2.69(1.03-6.99)$} \\
\hline Male & 13 & 94 & & \\
\hline Female & 7 & 136 & & \\
\hline \multicolumn{3}{|l|}{ Academic year } & \multirow{3}{*}{$0.091(0.76)$} & \multirow{3}{*}{$0.87(0.34-2.20)$} \\
\hline Undergraduate & 130 & 12 & & \\
\hline Intern & 100 & 8 & & \\
\hline
\end{tabular}

Continued 


\begin{tabular}{|c|c|c|c|c|}
\hline \multirow{2}{*}{ Demographic variable } & \multicolumn{2}{|c|}{ Problematic online gaming } & \multirow{2}{*}{ Chi-square (p value) } & \multirow{2}{*}{ OR $(95 \% \mathrm{CI})$} \\
\hline & Present & Absent & & \\
\hline \multicolumn{3}{|l|}{ Current residence } & \multirow{3}{*}{$0.114(0.73)$} & \multirow{3}{*}{$1.20(0.42-3.46)$} \\
\hline Home & 180 & 15 & & \\
\hline Hostel & 50 & 5 & & \\
\hline \multicolumn{3}{|l|}{ Internet use per day } & \multirow{3}{*}{$5.197(0.022)^{*}$} & \multirow{3}{*}{$4.43(1.27-15.56)$} \\
\hline Less than 3 hours & 101 & 3 & & \\
\hline More than 3 hours & 129 & 17 & & \\
\hline \multicolumn{3}{|c|}{ Frequency of online gaming } & \multirow{3}{*}{$6.231(0.013)$} & \multirow{3}{*}{$3.11(1.23-7.85)$} \\
\hline Less than once a week & 174 & 10 & & \\
\hline More than once a week & 56 & 10 & & \\
\hline \multicolumn{3}{|c|}{ Duration of a gaming session (hour) } & \multirow{3}{*}{$46.24(<0.001)^{*}$} & \multirow{3}{*}{$23.88(7.52-75.87)$} \\
\hline Less than 1 & 197 & 4 & & \\
\hline More than 1 & 33 & 16 & & \\
\hline
\end{tabular}

With yates correction.

Table 3: Association between problematic online gaming (POG) and measures of well-being, self-esteem and depressive mood.

\begin{tabular}{|llllll|}
\hline Health-related measure & $\begin{array}{l}\text { POG present } \\
\text { mean (SD) }\end{array}$ & $\begin{array}{l}\text { POG absent } \\
\text { mean (SD) }\end{array}$ & Mann-Whitney U & Z & P value \\
\hline Well-being & $19.29(6.99)$ & $23.97(5.88)$ & 1681 & -1.99 & 0.046 \\
\hline Self-esteem & $16.06(4.97)$ & $19.16(4.97)$ & 1560 & -2.39 & 0.017 \\
\hline Depressive mood & $8.47(3.22)$ & $5.23(4.24)$ & 3463 & 3.763 & $<0.001$ \\
\hline
\end{tabular}

\section{DISCUSSION}

About $82 \%$ of the study participants played video games which reflect the growing popularity of these games among the youth. The prevalence of internet gaming disorder varies worldwide and is estimated to be between $0.2 \%$ and $8.5 \% .^{15}$ The present study revealed a similar finding of prevalence of problematic online gaming of $8 \%$ among the undergraduate medical students of Goa medical college. It also revealed that higher proportion of male study participants $(12.1 \%)$ showed problematic online gaming than female study participants $(4.9 \%)$, which is consistent with the findings of Chih-Hung Ko et al and Wartber et al. ${ }^{16,17}$

As much as $21.6 \%(n=54)$ of the study participants used internet for more than 5 hours per day which explains the high penetration of internet in daily routine of these adolescents. This study finding is similar to study done by Bhatia et al in Madhya Pradesh, India. ${ }^{18}$ Also, there was a significant association between duration of internet use and problematic online gaming thus showing that problematic online gamers spend more time over online activities apart from playing online games than those without problematic online gaming behaviour. In contrast, a study done among Hungarian adolescents by Király, $\mathrm{O}$ et al reported that those who spend a lot of time using the Internet do not necessarily spend a lot of time playing online games. ${ }^{9}$

The current study showed that around $12.8 \%(n=32)$ of the study participants played online games daily. This finding is lower than the finding of the study done by
Wang et al in Honk Kong which revealed that $46 \%$ of the school students played video games daily. ${ }^{19}$ This difference may be due to the fact that this study examined only online gaming pattern in contrast to all video games examined by Wang et al apart from the difference in study participants. The study also revealed a significant association between frequency of gaming and problematic online gaming $\left(\chi^{2}=6.23, \mathrm{p}=0.013\right)$ which is a fairly expected finding as those who are addicted to online gaming tend to play these games more frequently than those who are not addicted.

In comparison to study done by Kim et al in South Korea which revealed that $33.4 \%$ of adults aged 20 to 49 years of age played online games for 1-2 hours per day, this study shows that only $22.9 \%$ of undergraduate medical students whose age ranged between 17-27 years played online games for 1-2 hours per day. ${ }^{20}$ A lower proportion may be because of the busy schedule of lectures and academic responsibilities in medical schools. Also, there was a significant association between duration of a gaming session and problematic online gaming $\left(\chi^{2}=50.32, p=<0.001\right)$ which shows that adolescents with problematic online gaming tend to play online games over longer periods than those without problematic online gaming. Online gamers spend more time gaming than those who play offline games, mostly because of the social nature of these games. They find online games more pleasant and satisfying than offline games and sometimes prefer playing games to real-life activities. ${ }^{21}$

The study reveals significant group differences between problematic online gaming and well-being, self-esteem 
and depressive mood. A lower score on well-being scale was seen in those who had problematic online gaming behaviour. This study finding is similar to the finding reported in a study Taiwanese adolescents by Ko et al. ${ }^{16}$ Online games are loaded with features like positive reinforcement with rewards within the virtual game world which help players gain a sense of achievement while playing these various online games.

A higher score on self-esteem scale was seen in those who did not have problematic online gaming which was similar to study findings reported by Chih-Hung Ko et al. ${ }^{16}$ This is likely to be because of the ability of online games to provide within the virtual game world with activities which make the gamers feel more confident and to which they can escape from a dissatisfying reality. The virtual game world also gives players recognition, reputation and admiration among many other online gamers who interact with each other at the same time in the social groups which are created and maintained as an integral part of the various online gaming platforms. This study also revealed significant group difference between depressive mood and problematic online gaming. Study participants with problematic online gaming showed a higher score of depressive mood as compared to those without problematic online gaming. This is consistent with the study findings reported by Wang et al in Taiwan and Ryu et al in Seoul, South Korea. ${ }^{22,23}$

The study had several limitations. The main limitations being its cross-sectional design are susceptible to recall bias which may have resulted in misclassification of the study participants. Also the study uses self-reported data which may give rise to social desirability bias. The study was done only among undergraduate medical students using online survey method which is susceptible to low response and selection bias and thus its findings cannot be generalised to the general population.

\section{CONCLUSION}

In conclusion, playing online games is a widespread activity among undergraduate medical students and a substantial proportion of these students exhibit addictive behaviours with regard to online gaming. Despite the limitations of the study, it attempts to extend the knowledge about problematic online gaming and its relationship with various health-related measures. Further research in terms of longitudinal studies involving larger samples of general population is needed to throw light on causal relationship between problematic online gaming and related factors.

\section{ACKNOWLEDGEMENTS}

We would like to acknowledge Statistician Dr Kulkarni of Goa medical college for providing the necessary guidance in analysis and interpretation of the results of this study.
Funding: No funding sources

Conflict of interest: None declared

Ethical approval: The study was approved by the Institutional Ethics Committee

\section{REFERENCES}

1. Rosenberg KP, Feder LC. Behavioural addictions: Criteria, Evidence, and Treatment. Elsevier. 2014; 415.

2. Mei S, Yau YHC, Chai J, Guo J, Potenza MN. Problematic Internet use, well-being, self-esteem and self- control: Data from a high-school survey in China HHS Public Access. Addict Behav. 2016;61:74-9.

3. Griffiths M. Online video gaming: what should educational psychologists know? Educational Psycholo Practice. 2010;26(1):35-40.

4. $\mathrm{Ng} \mathrm{BD}$, Wiemer-Hastings $\mathrm{P}$. Addiction to the Internet and Online Gaming. Cyberpsychology behavior. 2005;8(2).

5. Soper WB, Miller MJ. Junk-time junkies: An emerging addiction among students. School Counselor. 1983;31(1):40-3.

6. Shotton MA. Computer addiction?: A Study of Computer Dependency. 1st ed. Taylor \& Francis; 1989: 330.

7. American Psychiatric Association: Diagnostic and Statistical Manual of Mental Disorders. Fifth Edition. Arlington, VA: American Psychiatric Association; 2013.

8. ICD-11 - Mortality and Morbidity Statistics. Available at https://icd.who.int/browse11/1m/en\#/http\%3A\%2F\%2Fid.who.int\%2Ficd\%2Fentit y\%2F338347362. Accessed 13 July 2018.

9. Király O, Griffiths MD, Urbán R, Farkas J, Kökönyei G, Elekes Z, et al. Problematic internet use and problematic online gaming are not the same: findings from a large nationally representative adolescent sample. Cyberpsychol, Behav Soc Netw. 2014;17(12):749-54.

10. Pápay O, Urbán R, Griffiths MD, Nagygyörgy K, Farkas J, Kökönyei G, et al. Psychometric Properties of the Problematic Online Gaming Questionnaire Short-Form and Prevalence of Problematic Online Gaming in a National Sample of Adolescents. Cyberpsychol Behav Soc Netw. 2013;16(5):340-8.

11. Pavot W, Diener E, Colvin CR, Sandvik E. Further Validation of the Satisfaction With Life Scale: Evidence for the Cross-Method Convergence of Well-Being Measures. J Pers Assess. 1991;57(1):149-61.

12. Diener E, Emmons RA, Larsen RJ, Griffin S. The Satisfaction With Life Scale. J Pers Assess. 1985;49(1):71-5.

13. Baumeister RF, Campbell JD, Krueger JI, Vohs KD. Rosenberg self-esteem scale. 2003.

14. Spitzer RL. Patient health questionnaire: PHQ. New York State Psychiatric Institute, 1999. Available at 
https://search.library.wisc.edu/catalog/99990763510 2121. Accessed 13 July 2018.

15. Naskar S, Victor R, Nath K, Sengupta C. "One level more:" A narrative review on internet gaming disorder. Ind Psychiatry J. 2016;25(2):145-54.

16. Ko C-H, Yen J-Y, Chen C-C, Chen S-H, Yen C-F. Gender Differences and Related Factors Affecting Online Gaming Addiction Among Taiwanese Adolescents: J Nervous Mental Dis. 2005;193(4):273-7.

17. Wartberg L, Kriston L, Thomasius R. The Prevalence and Psychosocial Correlates of Internet Gaming Disorder. Dtsch Arztebl International. 2017;114(25):419-24.

18. Bhatia M, Rajpoot M, Dwivedi V. Pattern of internet addiction among adolescent school students of a North Indian city. Int J Community Med Public Health. 2016;2459-63.

19. Wang CW, Chan CLW, Mak K-K, Ho S-Y, Wong PWC, Ho RTH. Prevalence and Correlates of Video and Internet Gaming Addiction among Hong Kong Adolescents: A Pilot Study, 2014. Available at: https://www.hindawi.com/journals/tswj/2014/87464 8/. Accessed 23 July 2018.

20. Kim NR, Hwang SS-H, Choi J-S, Kim D-J, Demetrovics Z, Király O, et al. Characteristics and
Psychiatric Symptoms of Internet Gaming Disorder among Adults Using Self-Reported DSM-5 Criteria. Psychiatry Investigation. 2016;13(1):58.

21. $\mathrm{Ng} \mathrm{BD}$, Wiemer-Hastings $\mathrm{P}$. Addiction to the Internet and Online Gaming. Cyber Psychol Behavior. 2005;8(2):110-3.

22. Wang C-Y, Wu Y-C, Su C-H, Lin P-C, Ko C-H, Yen J-Y. Association between Internet gaming disorder and generalized anxiety disorder. J Behav Addict. 2017;6(4):564-71.

23. Ryu H, Lee JY, Choi A, Park S, Kim DJ, Choi JS. The Relationship between Impulsivity and Internet Gaming Disorder in Young Adults: Mediating Effects of Interpersonal Relationships and Depression, 2018. Available at: https://www.ncbi.nlm.nih.gov/pmc/articles/PMC587 7003/. Accessed on 22 July 2018.

Cite this article as: Bicholkar AU, Dias A, Mascarenhas V. Prevalence of problematic online gaming among undergraduate medical students and its relation to well-being, self-esteem and depressive mood in Goa, India. Int J Community Med Public Health 2019;6:1133-8. 